\title{
CONTRIBUIÇÕES TEÓRICAS PARA UMA REVISÃO DOS PRINCÍPIOS E PRÁTICAS DA REPRESENTAÇÃO DO CONHECIMENTO
}

\section{Leilah Santiago Bufrem \\ Helena de Fátima Nunes Silva \\ Sônia Maria Breda}

\begin{abstract}
RESUMO
Estudo sobre os aspectos lingüísticos de representação do conhecimento. Objetiva discutir os fundamentos teóricos da organização do conhecimento, em suas bases lingüísticas e culturais e elementos de representação, relacionando a teoria da interação verbal de Bakhtin com os princípios e práticas da representação do conhecimento. Fundamenta-se no pressuposto de que os princípios de representação não podem ser reduzidos às disciplinas e práticas que para elas contribuem. A partir das reflexões de Bakhtin, em Marxismo e filosofia da linguagem, são analisados quatro aspectos por ele apontados. O primeiro refere-se à interação entre interlocutores, fundamental para a comunicação e princípio fundador da linguagem. O segundo diz respeito à dependência do sentido do texto e da significação das palavras à relação entre sujeitos, sentido e significação construídos na produção e na interpretação dos textos pelos sujeitos. A precedência da intersubjetividade sobre a subjetividade é o terceiro aspecto observado, pois é na relação entre os interlocutores que se constroem os sujeitos produtores do texto. O quarto aspecto, a dupla noção de sociabilidade, é explorado pela análise da relação entre sujeitos ou interlocutores que interagem e a dos sujeitos com a sociedade. Esses aspectos compõem um processo decisivo para o diálogo ou interlocução entre vozes intermediadas pela percepção de mundo de cada um dos envolvidos, criando espaços de flexibilização intervenientes nos fundamentos teóricos sobre a organização e representação do conhecimento. Nessa direção, apontam-se caminhos e práticas, materializados em instrumentos resultantes da valorização dos elementos culturais, cognitivos, éticos e estéticos presentes no contexto de uma determinada sociedade ou comunidade.
\end{abstract}

PALAVRAS-CHAVE

Representação do conhecimento; Organização do conhecimento 


\title{
THEORETICAL CONTRIBUTION TO REVIEW THE PRINCIPLES AND PRACTICES OF KNOWLEDGE REPRESENTATION
}

\begin{abstract}
This paper discusses the theoretical fundaments of knowledge organization, in its linguistic and cultural bases. It tries to relate Bakhtin's theory, specifically verbal interaction, with the principles of knowledge representation, founded on the hypothesis that representation cannot be reduced to any of the practices or disciplines which contribute to it in an integrated mode. From reflexions of Bakhtin about dialogism in Marxism and the Philosophy of Language, it is analyzed four aspects he pointed out about the interaction among interlocutors concerning to the procedures to the documental representation. The first aspect refers to the interaction among interlocutors, which is essential to the communication and a founding principle of language. The second aspect concerns to the dependence of text meaning and words sense to the relation between subjects, as say, this sense and this meaning are built, during the production and interpretation of the texts, by the subjects. The precedence of intersubjectivity to subjectivity is the third aspect observed, since it is in the relation among the interlocutors that the text producer subjects are constructed. Considering the fourth aspect, the double notion of sociability is explored by the analysis of the relation among subjects or interlocutors that interact, and that between subjects and society. It is recognized that this process affects the theoretical fundaments of knowledge organization and representation, since it results from a dialog or a conversation among the subjects who interact in this space in which the voices are intermediated by the world perception of each one of the people involved. In this sense, it points out some ways and practices to the comprehension and consequent representation of knowledge, as materialized in some tools that result in valorizing cultural, cognitive, ethical and esthetic elements present in the context of a determined society or community.
\end{abstract}

\section{KEYWORDS}

Knowledge representation; Knowledge organization. 


\section{INTRODUÇÃO}

As transformações históricas determinantes dos modos de criar, registrar, reproduzir e acessar o conhecimento vêm chamando a atenção dos especialistas e usuários da informação para a presença e a força concreta dos elementos presentes na leitura, tradução e representação do conteúdo de documentos textuais. Constitui-se especial desafio a expressão e posterior descrição dos conceitos mediante as palavras, apresentadas como referência inevitável nos processos e resultados da análise de conteúdo documental por Moreiro González (2004). Seja utilizada livremente, como na linguagem natural, seja controlada por um sistema que a legitima para representar conceitos, a palavra converte-se em fim e meio para o autor, o leitor e o analista no fértil campo da análise e representação documentais do conteúdo dos textos.

O reconhecimento de que os aspectos de representação documentária não podem ser reduzidos a nenhuma das disciplinas e práticas que para elas contribuem de forma integrada leva-nos a considerar que a representação do conhecimento, como campo teórico ou metodológico, requer a discussão de princípios como o contexto do conhecimento, a natureza dos conceitos, a relação entre os conceitos e o sistema de conceitos e que, por outro lado, o princípio fundante da linguagem é a interação entre interlocutores.

Embora essa posição seja aceita pelos profissionais da informação e gestores do conhecimento, nem sempre são reconhecidas as limitações que envolvem o trabalho de especialistas e técnicos quando da elaboração de instrumentos ou serviços necessários ao processo de representação e organização do saber. Isso porque a crença nas possibilidades de universalização dos produtos representativos do conhecimento registrado e na superação das limitações das tecnologias digitais na área de documentação relativizam ou idealizam uma simplificação da infinita rede de conexões entre documentos e suas representações, assim como das conseqüências dessa complexidade sobre essa prática profissional.

Ao discutir os fundamentos teóricos da organização do conhecimento, relacionando a teoria da interação verbal de Bakhtin com os princípios e práticas da 
representação do conhecimento, este estudo busca contribuir para ampliar o campo de visão sobre o tema.

\section{DA INTERAÇÃO ENTRE INTERLOCUTORES À REPRESENTAÇÃO DOCUMENTÁRIA}

A percepção de que as formas como são organizados os conhecimentos e suas representações são construções culturais, a partir de situações e modos de produção concretos, orienta a eleição de alguns princípios para a compreensão das bases de representação. De fato, ao se analisarem diacronicamente as tentativas de classificar os conhecimentos para melhor organizá-los, percebe-se que as classificações humanas, desde as filosóficas clássicas, passando pelos sistemas modernos e contemporâneos, procuram estabelecer categorias a partir de critérios intimamente relacionados com seus propósitos de organização. Se, por um lado, atestam a criatividade e interoperabilidade alcançáveis no trabalho com a representação do conhecimento, por outro, traduzem o ideal de padronização terminológica.

Como diferentes contextos são determinados pelas suas condições econômicas específicas, pelas necessidades que a eles se apresentam, pelas estruturas e códigos que estabelecem, pelas situações concretas que os caracterizam e que definem as emergentes soluções aos problemas de organização do conhecimento, resultam diferenciados modos de analisar, interpretar e representar conhecimentos.

Assim, encontra-se nas reflexões de Bakhtin, em Marxismo e filosofia da linguagem campo fértil para analisar quatro aspectos por ele apontados sobre o dialogismo e que nos permitem estabelecer uma relação com os procedimentos para a representação documentária. O primeiro aspecto refere-se à interação entre interlocutores, fundamental para a comunicação e princípio fundador da linguagem. O segundo aspecto diz respeito à dependência do sentido do texto e da significação das palavras à relação entre sujeitos, ou seja, esse sentido e essa significação constroem-se na produção e na interpretação dos textos pelos sujeitos. A precedência da intersubjetividade sobre a subjetividade é o terceiro aspecto observado para este estudo, pois é na relação entre os interlocutores que se constroem os sujeitos produtores do texto. Quanto ao quarto aspecto, a dupla noção de sociabilidade é explorada pela análise 
da relação entre sujeitos ou interlocutores que interagem e a dos sujeitos com a sociedade.

Considerando-se, com Bakhtin, que a linguagem é fundamental para a comunicação e que a interação entre interlocutores a concretiza, destacam-se aspectos interferentes na interpretação do fenômeno da comunicação. Superando a associação de interdependência compositiva dos documentos, com suas duas estruturas, a externa e a abstrata, compreensíveis para o leitor documentarista que, sem atuar como autor da mensagem, torna-se emissor ou viabilizador da intermediação necessária entre ela e seu destino, a prática de leitura reconhece também níveis descritivos e de análise que introduzem esse mediador às fases ou momentos do processo, mais especificamente, o reconhecimento, a redução e a representação. Nelas entram em jogo os referenciais semânticos que nos levam à compreensão do que se entende por texto e por documento e à superação da dicotomia significado/significante pela união dos planos sintático, semântico e pragmático no discurso. A língua, entretanto, não é uma estrutura independente, mas fundamentada na interação entre interlocutores. A multicitada metáfora da ponte elucida essa posição: “Toda palavra serve de expressão a um em relação ao outro, isto é, em última análise, em relação à coletividade. A palavra é uma espécie de ponte lançada entre mim e os outros. Se ela se apóia sobre mim numa extremidade, na outra se apóia sobre o meu interlocutor. A palavra é o território comum do locutor e do interlocutor” (BAKHTIN, 2004, p. 113). Desse modo, mesmo que em determinado momento o locutor seja dono da palavra, não se pode negar que essa palavra tenha sido escolhida dentro de um estoque social de signos disponíveis. Essa seleção intencional procede do referencial concreto e comum aos interlocutores. Da mesma forma, o mediador ou leitor,, ao interpretar o texto para representá-lo, deve concebê-lo como socialmente dirigido e precisamente situado, aceitando que a estrutura da enunciação é determinada pela situação social mais imediata e o meio social mais amplo.

Tem-se a linguagem assumida, viva, como atividade social, consciência prática através da qual a realidade é apreendida. Como elucida Raymond Williams (1977) ao referir-se às teorias do Círculo Bakhtin, a linguagem enquanto consciência prática está impregnada e impregna todas as atividades sociais, inclusive as atividades produtivas. 
As tarefas de seleção e de atribuição dos termos pelo profissional da informação, portanto, além de inspiradas nas necessidades dos usuários, são principalmente fundamentadas no contexto das culturas às quais pertencem e nas experiências dos interlocutores nesse processo interativo. Processam-se diante do universo de possibilidades para representação dos conceitos selecionados, desde vocabulários controlados às linguagens livres e às possíveis circunstâncias que levam à decisão de se incluir um termo como representante do conteúdo original, como nos orienta Moreiro (2004).

O segundo aspecto analisado parte da dependência do sentido do texto e da significação das palavras à relação entre sujeitos, ou seja, esse sentido e essa significação constroem-se na produção e na interpretação dos textos pelos sujeitos. O ambiente em que se processa essa interação participa da construção dos significados e dos sentidos, permitindo a interação entre realidade sócio-histórica, tecnologias de comunicação e informação disponíveis, bem como a interpretação dos sujeitos interlocutores, com suas possibilidades intra e intersubjetivas. Dessa relação intersubjetiva que se verifica em ambiente que se define como estruturante, depende, portanto, o sentido do texto e da significação do que se produz como sua representação. O ambiente estruturante para a relação intersubjetiva pode se dar na vivência de uma prática, entendida como "um fazer num contexto histórico e social que dá estrutura e significado para o que o ser humano realiza. Neste sentido, a prática é sempre uma prática social. Tal conceito de prática inclui o conhecimento tácito... o que é dito... representado... assumido. Inclui linguagem, ferramentas, documentos, imagens e símbolos, como regras bem definidas, critérios específicos, procedimentos solidificados, regulamentos e contratos...”(WENGER apud SILVA, 2004, p. 73).

Ao estabelecermos uma relação desse segundo aspecto apontado por Bakhtin com a representação documentária, é possível afirmar que a prática vivenciada pelos profissionais da informação, em determinada área do conhecimento, estrutura e dá sentido aos produtos informacionais por eles produzidos. Embora a representação documentária esteja apoiada em teorias, na prática algumas questões estão sempre presentes, ou seja, como representar adequadamente as informações sem comprometer o seu significado? Ou como resolver o problema da quase ausência de articulação entre os 
descritores para a recuperação de informações veiculadas pelos textos? As palavras (descritores) são “neutras”. É a condição de referência a determinados contextos que lhes confere o significado. É o significado que focaliza o ser humano no mundo e na história e ao aceitarmos essa dependência vemos favorecida a compreensão de que a intersubjetividade desempenha um papel decisivo sobre a subjetividade, o terceiro aspecto aqui analisado.

Aceitar a precedência da intersubjetividade sobre a subjetividade significa considerar que na relação entre os interlocutores se constroem os sujeitos produtores do texto. A subjetividade não se reconhece somente em um eu individual, mas também em um nós e em uma intersubjetividade. Nesse sentido, a pessoa é vista como um ser flexível, aprendiz e inovador, derivada dos repertórios da transitoriedade de mundos e da mudança para o novo. Ela é capaz de articular as diferenças, unir as múltiplas dimensões e congregar os inúmeros valores, buscando sua inserção, sua inter-relação com os outros sujeitos. (DAVEL e VERGARA, 2001, p. 46). Dessa maneira, a noção de subjetividade passa a entender-se como subjetividade intersubjetiva. Não se pode desconsiderar o outro, o que pensa, sente, percebe, pois uma das características do ser humano consiste nas suas capacidades de criar, compreender, transcender, comportarse, e elas são acrescidas e desenvolvidas nas relações intersubjetivas.

Com o advento da Internet, a inter-relação dos sujeitos foi intensificada, facilitando a interação entre produtores e leitores. O papel da rede passa a ser de mediador privilegiado nesse universo real conhecido, agora não mais dividido entre dois mundos, o da subjetividade, onde estava imerso o seu interior, o seu eu, e o da intersubjetividade, em que, por meio dos sentidos, estava em simbiose com o mundo e relacionava-se com seus semelhantes.

Há que se respeitar a relação entre a Internet e o processo de análise documentária. Este passa por questões de recuperação e pelas relações semânticas dele emergentes, em que os termos lingüísticos são estabelecidas por métodos, tais como de agrupamento e classificação, e facilitados pela indexação automática. No entanto, precedente a essa construção, automática ou não, a intersubjetividade fundamenta essas relações e as linguagens representativas do conteúdo dos documentos, que se concretizam graças às condições funcionais e ferramentas construídas pelos sujeitos atuantes no processo. A análise da relação entre sujeitos ou interlocutores que interagem 
e a dos sujeitos com a sociedade expõe a dupla noção de sociabilidade. A par de uma relação entre sujeitos, ou seja, entre interlocutores ou interagentes, ocorre uma relação entre os sujeitos e a sociedade. A noção de sujeito de Bakthin é, portanto, a de "sujeito social, caracterizado por pertencer a uma classe social e em que dialogam os diferentes discursos da sociedade” (BARROS, 2001, p. 28).

As relações sociais possibilitam que os significados sejam negociados. A negociação de significado abarca as histórias compartilhadas de aprendizagem, relacionamentos, interações e práticas comuns. É um processo complexo, envolvendo o fazer, o conversar, o pensar, o sentir e o pertencer (WENGER apud SILVA, 2004, p.7678). Na interação dos sujeitos com a representação documentária existe uma abstração, incluindo, além de outros elementos, o conhecimento tácito. Este, embora difícil de ser verbalizado, é decisivo para os modos de concepção e concretização das atividades pelo sujeito. É necessário um domínio de conhecimento, tanto para entender como para utilizar a metalinguagem, produto da representação. Ou seja, os descritores estão relacionados com a flexibilidade interpretativa das representações de cada pessoa e são utilizados como representações do conhecimento, permitindo que este seja socializado. Os produtos obtidos pelo processo de representação documentária, em seus diversos graus de redução semântica (resumos, índices, referências bibliográficas), organizados em diferentes suportes e bases de conhecimento, são disseminados em função das diferentes demandas por informação, resultando na dupla noção de sociabilidade, apontada por Bakhtin.

Infere-se dessa análise que se a palavra assume papel primordial nessa sociabilidade, pois é a partir dela que o sujeito se constitui e é constituído, a linguagem e a história, fundamentais para a compreensão da realidade, impõem-se como acompanhantes indispensáveis de toda representação do conhecimento. 


\section{CONSIDERAÇÕES FINAIS}

Na tentativa de aproximação das reflexões de Bakhtin com os princípios e práticas da representação do conhecimento, destaca-se a idéia de que esse processo não se reduz a qualquer das disciplinas e práticas que para ele contribuem. Participam da elaboração de instrumentos ou serviços necessários ao processo de representação e organização do conhecimento condições de natureza lingüística, semântica, intersubjetiva e social que interagem nesse processo.

Espera-se que as reflexões deste trabalho possam contribuir para esclarecer os princípios e as formas como são organizados os conhecimentos e suas representações, bem como sua integração com as construções culturais, modificadas pelas práticas desenvolvidas para criar, registrar, reproduzir e acessar esses conhecimentos. Nesse sentido, as considerações de Bakthin podem apontar caminhos e práticas para a compreensão e a conseqüente representação do conhecimento, materializadas em instrumentos que resultem da valorização dos elementos culturais, cognitivos, éticos e estéticos presentes no contexto de uma determinada sociedade ou comunidade. Reconhece-se, entretanto que esse processo pode representar a exclusão de saberes e de enfoques, mas resulta de um diálogo ou de uma interlocução entre os sujeitos interatuantes nesse espaço em que as vozes se apresentam intermediadas pela percepção de mundo de cada um dos envolvidos. O contexto em que se realiza essa interlocução, no momento da enunciação, é carregado pelo simbólico e dependente do esforço realizado para a comunicação. As eventuais lacunas de compreensão podem ser reconstituídas pelas impressões e experiências de cada sujeito.

Portanto, toda a discussão sobre a natureza do trabalho do profissional da informação teria de se fundamentar, primeiro, sobre a natureza da linguagem em geral em sua existência, como parte do mundo social da cultura e não das puras formas. Além dos elementos constituintes do que se produziu como vocabulário controlado ou sistema lingüístico de formas reiteráveis, como já se idealizou, está a verdadeira realidade a representar, revelando a criatividade dos sujeitos que constroem a língua. Do mesmo modo, para Bakhtin, todo evento da linguagem é a atualização de uma relação entre sujeitos históricos e sociais. 


\section{REFERÊNCIAS}

BARROS, D. L. P. Contribuições de Bakhtin às teorias do texto e do discurso. In: FARACO, C.A.; TEZZA, C.; CASTRO, G. Diálogos com Bakthin. Curitiba: Ed. da UFPR, 2001.

BAKHTIN, Mikhail. Marxismo e filosofia da linguagem. São Paulo: Hucitec, 2004.

BAKHTIN, Mikhail. Problemas literarios y estéticos. La Habana: Arte y Literatura, 1986.

BOURDIEU, Pierre. O poder simbólico. Lisboa: Difel; Rio de Janeiro, Bertrand Brasil, 1989.

DAVEL, E.; VERGARA, S. C. Gestão com pessoas, subjetividade e objetividade nas organizações. São Paulo: Atlas, 2001.

MOREIRO GONZÁLEZ, José Antonio. El contenido de los documentos textuales: su análisis y representación mediante el lenguaje natural. Gijón: Ediciones Trea, 2004.

SILVA, H. F. N. Criação e compartilhamento de conhecimento em comunidades de prática: uma proposta metodológica. 2004. 212f. Tese (doutorado em Engenharia de Produção). Universidade Federal de Santa Catarina, Florianópolis, 2004.

WENGER, E. Communities of practice: learning, meaning and identity. Cambridge: Cambridge University Press, 1998.

WILLIAMS, R. Culture and society. London: Lawrence and Wishart, 1977.

WILLIAMS, R. Marxism and literature. Oxford: Oxford University Press, 1977. 
LELLAH SANTIAGO BUFREM

Profa Titular do Departamento de Ciência e Gestão da Informação

Universidade Federal do Paraná

Fone: 41 3360-4422

E-mail: leilah@ufpr.br

\section{HELENA DE FÁTIMA NUNES SILVA}

Profa Adjunta do Departamento de Ciência e Gestão da Informação Universidade Federal do Paraná

Fone: 41 3360-4425

E-mail: helenanunes@ufpr.br

SÔNIA MARIA BREDA

Profa $^{a}$ Assistente do Departamento de Ciência e Gestão da Informação

Universidade Federal do Paraná

Fone: 41 3360-4427

E-mail: breda@ufpr

Recebido em: $17 / 11 / 2005$

Aceito: $20 / 12 / 2005$ 